\title{
Beyond the "Fab Lab" model: design and other spaces of creation using digital fabrication technologies
}

XXIV International Conference of the Iberoamerican Society of Digital Graphics Medellin | Colombia

\author{
Rodrigo Scheeren \\ Universidade de São Paulo | Brasil | rodrigoscheeren@gmail.com \\ David M. Sperling \\ Universidade de São Paulo | Brasil | sperling@sc.usp.br
}

\begin{abstract}
Laboratories based on the "Fab Lab" model have spread virtuously around the world in the past two decades. Over the years, some alternatives have emerged, establishing themselves in a more contextualized way. The article presents "other creative spaces", involving case studies from three laboratories in South America: "Fábrica Diseño e Innovación" (Argentina), "Fab Lab Livre SP" (Brazil), and "Exploratorio: taller público de experimentación" (Colombia). In this way, it shows an analysis of the functioning of these laboratories in each condition, the practices emerging from these places related to the sociotechnical adequacy of digital fabrication technologies into their realities.
\end{abstract}

Keywords: Fab Lab; Digital fabrication; Social innovation; Sociotechnical adequacy; Case studies.

\section{INTRODUÇÃO}

Desde o início dos anos 2000, a proposta dos "Fab Labs", enquanto espaços de trabalho com tecnologias de fabricação digital e outras ferramentas utilizadas como suporte para iniciativas de criação a partir do fazer, está se difundindo por diversos países, formando uma rede global. A história por trás dessa constituição já é bem conhecida em nosso meio. Abreviação de "Fabrication Laboratory", sua concepção surgiu a partir da disciplina "how to make (almost) anything", no ano de 1998, por Neil Gershenfeld, membro do Center for Bits and Atoms (CBA), no Massachusetts Institute of Technology (MIT), articulando um modelo que pudesse ser levado para além do instituto, a partir de 2002, com o financiamento do National Science Foundation, dos Estados Unidos.

Para Gershenfeld, a difusão dos Fab Labs pelo mundo representa parte de um "'movimento maker' mais amplo de high-tech do-it-yourselfers, que estão democratizando o acesso aos meios modernos de se fazer coisas" (Gershenfeld, 2012, p. 48). Isso significa que a sua difusão seguiu na esteira da própria dinâmica de criação de projetos de máquinas e eletrônicos possibilitados pelo mais fácil acesso a dispositivos periféricos, em conjunto ao compartilhamento de informações em rede, como foi o caso do RepRap project. A aderência ao modelo acontece, após o cumprimento de uma série de pré-requisitos, de maneira voluntária ou por associação instituída. Apesar de pertencerem à rede, esses laboratórios apenas "seguem o modelo fab lab MIT", segundo Sherry Lassiter (Fab Wiki, n.d.).

A América do Sul conta com 218 espaços cadastrados, até o momento, na página web "FabLabs.io": 16 na Argentina, 3 na Bolivia, 123 no Brasil, 19 no Chile, 12 na Colômbia, 10 no Equador, 1 na Guiana Francesa, 5 no Paraguai, 21 no
Peru, 1 no Suriname, 4 no Uruguai, e 3 na Venezuela. Apesar do número de registros, alguns laboratórios já não estão mais em atividade, por uma série de fatores, como a difusão das impressoras 3D para uso doméstico e pessoal, o fornecimento de serviços similares por outras empresas, e os custos de manutenção e funcionamento do espaço.

O modelo-marca "Fab Lab", definiu diretrizes tecnológicas, espaciais e princípios de funcionamento (Fab Wiki), uma plataforma virtual que torna visíveis as informações sobre laboratórios associados no mundo (Fablabs.io), uma fundação para financiamento da ampliação da rede (Fabfoundation) e cursos de aprendizagem e experiências similares à disciplina de 1998 (Fab Academy). Desse modo, surgiu como uma referência no horizonte de interessados em novas tecnologias. Apesar de suas virtudes e certa flexibilidade do programa, manteve-se como um modelo genérico, exigindo equipamentos mínimos, ditando características de acesso e avaliando os laboratórios por classificação de conformidade. Com o passar dos anos, variações e alternativas a esse modelo foram surgindo, muitos deles mantendo-o como referência, mas também procurando se fundamentar e se instituir de maneira mais contextualizada. Tais iniciativas vêm se orientando menos pelo reconhecimento de seus espaços, e mais pelo foco em atividades que possam ser desempenhadas e relações constituídas localmente.

O artigo apresenta uma análise de "outros espaços de criação", a partir de estudos de caso de três laboratórios selecionados na América do Sul: "Fábrica Diseño e Innovación" (Argentina), "Fab Lab Livre SP" (Brasil), e "Exploratorio: taller público de experimentación" (Colômbia). O objetivo do trabalho é promover uma análise circunscrita e aprofundada acerca das dinâmicas 
de funcionamento de laboratórios representativos em nosso contexto, fornecendo insights sobre as práticas emergentes desses laboratórios e de suas realidades. A investigação estabelece similaridades e diferenças entre o modelo Fab Lab e os laboratórios escolhidos na região. Desse modo, contribui com uma perspectiva acerca das características de cada local e verifica as potencialidades de suas atividades, arranjos espaciais e processos relacionados às comunidades culturalmente situadas, ampliando o espectro de discussão do tema.

Durante os últimos anos, estudos associados aos Fab Labs abordaram variados aspectos, que incluem práticas do fazer, atividades educacionais, serviços, produção de protótipos, pesquisa e negócios. De acordo com Troxler (2016), os "Fab Labs" são a fonte de ressurgimento de um movimento maker, que envolve o compartilhamento de conhecimentos, a criação de valores comuns e a inspiração para que as comunidades locais se integrem ao processo. $\mathrm{Na}$ área da educação, os laboratórios podem prover um novo tipo de alfabetização, habilidades e capacidades intelectuais, por meio de fluência computacional e de fabricação (Blikstein \& Krannich, 2013). Os espaços de fabricação podem também ser base para o fornecimento de competências para a inovação e até a oportunidade de oferecer recursos para o empreendedor individual (Mortara \& Parisot, 2016).

Contudo, também surgem limitações e dificuldades na efetivação dos programas acima citados, veiculados em manifestos, manuais ou artigos teóricos. Considerados os fatores culturais, esses discursos podem estar professando um certo significado de tecnologia que, infelizmente, pode crescer longe de uma compreensão mais crítica e democrática das mesmas (Nascimento, 2014). Mesmo com o estímulo de princípios de abertura, democratização, empoderamento e compartilhamento de informações, os Fab Labs e o movimento maker podem facilmente se associar a concepções individualizantes, flexibilização do trabalho especializado e suprimir o que há de possibilidade mínima para a construção coletiva na sociedade (Fonseca de Campos \& Dias, 2018). Soderberg (2013) reforça a preocupação sobre a constituição das plataformas de trabalho abertas que poderiam, em alguns casos, conduzir os trabalhadores à autoexploração, e acerca da ideação do uso das tecnologias para a fabricação de produtos para se tornarem bens de consumo

Diante da gama de características e situações anteriormente mencionadas, mais frequentemente encontradas em análises situadas na Europa e na América do Norte, pretendemos nos distanciar de narrativas e conclusões generalistas, repetidamente encontradas nos artigos relacionados ao tema dos Fab Labs. Assim, partindo da perspectiva crítica epistêmica em relação à colonização do imaginário e do saber (Mignolo \& Walsh, 2018), apresentamos laboratórios sul-americanos que estão explorando identidades políticas próprias (Mignolo, 2008), inseridos em condições culturais híbridas de implementação (García Canclini, 2015) e resultando em processos voltados à inovação social (Manzini, 2015).

\section{METODOLOGIA}

Os métodos utilizados no estudo são a revisão da literatura, questionário online com perguntas mistas (Lune \& Berg, 2017), estudos de caso dos laboratórios (Wang \& Groat,
2015), nos quais foram realizadas as visitas técnicas e entrevistas semiestruturadas, durante datas específicas em 2018 e 2019; e coleta de informações complementares, para efetuarmos análises comparativas. O trabalho é uma investigação exploratória que faz parte da pesquisa em andamento, intitulada "Fabricação digital na América do Sul: estratégias, processos e artefatos para a arquitetura e o design", desenvolvida no Instituto de Arquitetura e Urbanismo da USP. Os laboratórios foram selecionados dentro de um quadro mais amplo já mapeado, refletindo distintas regiões culturais e a implantação de locais associados aos ecossistemas tecnológicos em desenvolvimento.

A revisão bibliográfica abrange os diversos temas de pesquisa ligados aos "Fab Labs". Os questionários que apreendem dados quantitativos e qualitativos, foram formulados para se obter informações institucionais e de infraestrutura, dados sobre os usos das tecnologias de fabricação e a identidade da produção. As visitas técnicas aos laboratórios forneceram uma percepção do espaço, do ambiente, da infraestrutura e das atividades realizadas. As entrevistas foram efetuadas com os coordenadores e profissionais responsáveis, com perguntas baseadas na formação dos espaços, vínculos institucionais, produção e perspectivas futuras acerca dos laboratórios. As informações complementares foram obtidas através de acesso às respectivas páginas web e de outras redes, reportagens e artigos. As análises se desdobraram por meio de quadros comparativos que sintetizam características relevantes de cada laboratório.

\section{RESULTADOS}

Na América do Sul, a inserção dos "Fab Labs" teve início em 2009, com a instalação em Lima, no Peru (Fab Lab Lima/Fab Lab UNI), e em 2011, em São Paulo, no Brasil (Fab Lab SP). Antes dessas datas, já estavam sendo adquiridas máquinas de fabricação digital, por instituições de ensino e pesquisa, mas de maneira geograficamente dispersa em nosso continente. A análise dessa perspectiva mais ampla de implementação das novas tecnologias e dos laboratórios está bem documentada em publicações anteriores (Herrera \& Juárez, 2012; Sperling et al., 2015). Diferentemente dessa abordagem, a investigação aqui proposta foca em três laboratórios, com características singulares em relação ao campo mais abrangente.

\section{ESTUDO DE CASO 01 - FÁBRICA DISEÑO E INNOVACIÓN}

Criado em 2016, na cidade de Buenos Aires, Argentina, a "Fábrica" está inserida no parque de exposição científica denominado "Tecnópolis". É um espaço público financiado pelo Ministério da Ciência, Tecnologia e Inovação da Nação. Apresenta-se de acordo com um espaço que utiliza o design como fator estrutural para a inovação social, fornecendo suporte para áreas estratégicas do governo, como educação, saúde e habitação, ou mesmo incluindo demandas de empresas e da sociedade civil. Logo, funciona como um "programa que está aberto a comunidade, com foco em ciência, tecnologia e design", um local centralizador de demandas e atividades, disseminando serviços, experiências e táticas práticas de design aplicado a projetos. Além dos procedimentos de capacitação e produção, o espaço já foi utilizado para fóruns e exposições dos resultados. O laboratório possui uma série de convênios com outros organismos públicos, 
como Universidades, que ministram cursos de design, e Institutos de Tecnologia, para que, inclusive, os projetos desenvolvidos possam ser replicados nas distintas províncias do país.

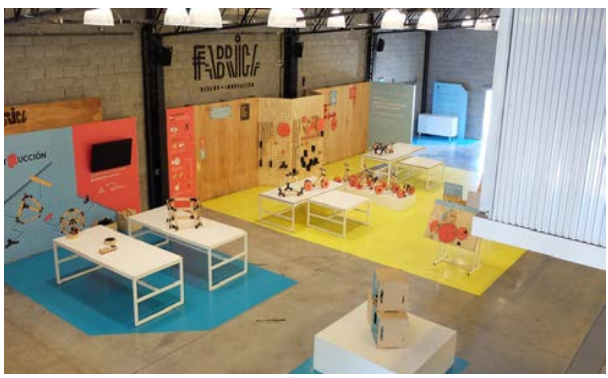

Figura 1: Interior da "Fábrica", mostrando o espaço aberto de mostra e interação com objetos produzidos.

O espaço dispõe de três impressoras 3D, uma cortadora laser e uma fresadora CNC grande. Além disso, conta com com equipamentos e ferramentas para carpintaria, e produção têxtil. A escala dos artefatos produzidos é pequena ou média, de objetos de design a mobiliário. Segundo as informações coletadas, a maior dificuldade encontrada é a obtenção de recursos financeiros. A equipe de trabalho atua construindo o processo criativo em colaboração com os usuários em oficinas e projetos sob demanda. Segundo as coordenadoras, a partir das demandas de distintos atores, organiza-se uma agenda de trabalho, estabelecendo-se uma "sociedade" pela qual são definidas as etapas de processo, investigação, desenvolvimento, prototipagem e validação no território.

Isso acontece por meio de projetos em que se mapeiam os atores envolvidos em cada região, a fim de se trabalhar colaborativamente. Assim, é fundamental "trabalhar entendendo os problemas e as necessidades da comunidade [...], tentando não impor soluções, mas construí-las em colaboração com os usuários, tornando-os parte do processo criativo e de avaliação". Dessa maneira, as tecnologias de fabricação digital são aplicadas como suporte para o refinamento dos projetos, não necessariamente sendo utilizadas para a sua manufatura.

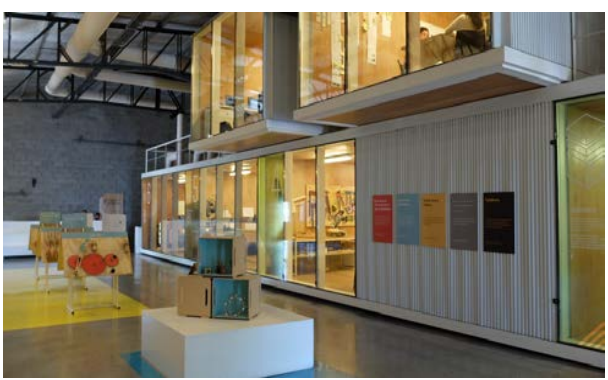

Figura 2: Interior da "Fábrica", mostrando os ateliês de produção, com máquinas e ferramentas.

\section{ESTUDO DE CASO 02 - FAB LAB LIVRE SP}

Criado em 2015, na cidade de São Paulo, Brasil, o Fab Lab Livre SP é uma rede de laboratórios descentralizada que conta com 12 unidades espalhadas pelo município. Todos os espaços são públicos e financiados pela Prefeitura Municipal da Cidade de São Paulo, mas a gestão dos serviços oferecidos acontece em colaboração com uma empresa privada. Alguns laboratórios surgiram da transformação dos antigos "Telecentros" - instalações públicas de uso gratuito de computadores e acesso à internet -, outros foram inseridos em salas de espaços culturais já existentes. Assim, a formação anterior focada na inclusão digital, migrou para os novos modos de fazer e fabricar. Os laboratórios são espaços abertos e acessíveis para o aprendizado, a criação e o desenvolvimento de projetos com suporte da equipe de cada centro. Para além dos cursos de curta duração, há o foco no desenvolvimento de projetos em empreendedorismo, educação e propostas para a comunidade. Nesses processos, "têm surgido muitos parceiros que também querem desenvolver projetos com Fab Lab, muitas vezes são projetos realmente de desenvolvimento de produtos mas também muita coisa relacionada à educação, parceiros que querem dar aula".

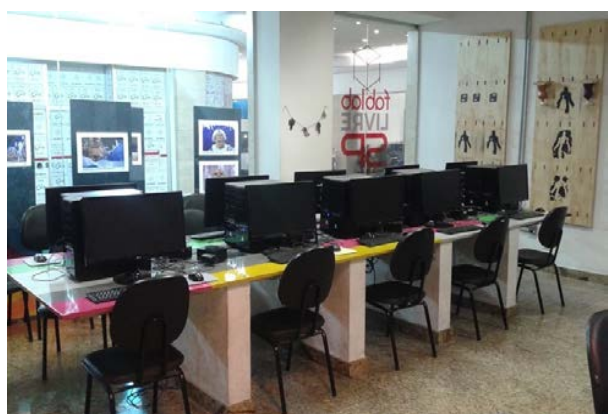

Figura 3: Interior de um dos laboratórios "Fab Lab Livre" e sua área de trabalho.

Os espaços são categorizados por laboratório "grande" e "pequeno", com diferença de distribuição de equipamentos. No primeiro, há três impressoras $3 \mathrm{D}$, uma cortadora laser $\mathrm{e}$ fresadora CNC (uma mini e outra grande); no segundo, há duas impressoras 3D, uma cortadora laser e uma fresadora CNC grande; além de ferramentas para carpintaria, eletrônica e produção têxtil. A escala dos artefatos produzidos é pequena ou média, como modelos, objetos de design e instalações. Segundo informações coletadas, a maior dificuldade de operação é a infraestrutura ainda limitada dos laboratórios. Mesmo assim, eles podem ser considerados espaços receptivos às demandas externas.

Segundo os coordenadores, na implantação, foram priorizadas regiões onde havia pouco acesso aos equipamentos mas um potencial de uso e organização latente, com foco na territorialização desses espaços, e que contribuíssem para fomentar o desenvolvimento de projetos específicos, pelas comunidades, com as tecnologias de fabricação. Além disso, a articulação com a Secretaria da Cultura e com a da Educação foi de fundamental importância. Ao contrário das atividades iniciais, que estavam muito baseadas em propostas pessoais, atualmente, há um maior incentivo para parcerias e projetos orientados, principalmente com instituições de pesquisa, para que sejam desenvolvidos nos espaços projetos colaborativos a longo prazo. 


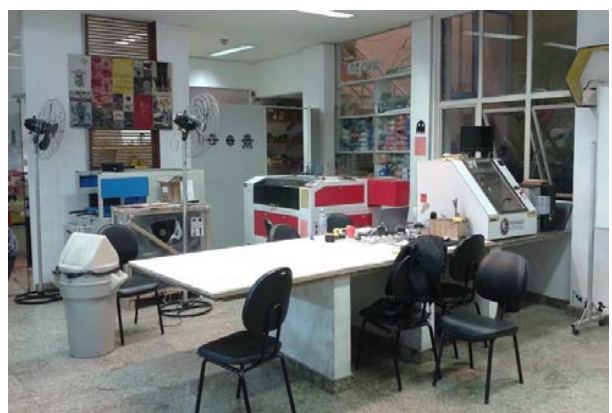

Figura 4: Interior de um dos laboratórios "Fab Lab Livre" com máquinas e local de trabalho.

\section{ESTUDO DE CASO 03 - EXPLORATORIO: TALLER PÚBLICO DE EXPERIMENTACIÓN}

Criado em 2016, na cidade de Medellin, Colômbia, o "Exploratorio" integra o conjunto de equipamentos e de infraestrutura urbana denominado "Parque Explora", que impacta de forma expressiva na zona norte do município. É um espaço público, financiado pela Secretaria de Desenvolvimento Econômico da Prefeitura de Medellín, em conjunto com o Parque Explora e outros órgãos governamentais de fomento à inovação, e que busca captar complementarmente recursos privados. O laboratório é um local aberto com oficinas e suporte para acolher demandas das comunidades próximas e trabalhar em colaboração com agentes locais na produção, além de abrigar exibições e eventos multimídia. Antes de seu estabelecimento no local, o projeto foi gestado por meio de laboratórios de experimentação nos territórios de comunidades periféricas da cidade. O seu objetivo é, segundo o coordenador, a apropriação, ou seja, "tornar concreta a ideia do laboratório como possibilidade criativa, saltar do exercício de formação para gerar processos de laboratório e criação de coisas".

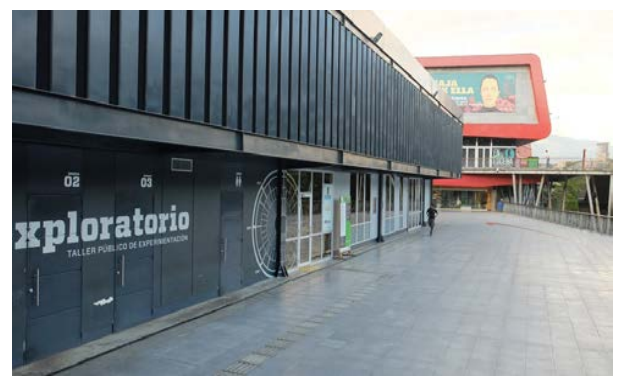

Figura 5: Acesso ao "Exploratorio", junto a praça do "Parque Explora".

O espaço conta com uma impressora 3D, uma cortadora laser e uma fresadora CNC grande, além de ferramentas para carpintaria e eletrônicos, produção têxtil e audiovisual. A escala dos artefatos produzidos é pequena ou média, gerando desde objetos das oficinas até dispositivos e instalações. Segundo dados coletados, a maior dificuldade encontrada é a obtenção de recursos financeiros e de materiais a serem utilizados durante as atividades. Apesar disso, o modo de funcionamento do espaço busca agregar múltiplas atividades e usos, pretendendo engajar a participação da comunidade em diferentes níveis de ações.
Segundo os coordenadores, a própria ideia apropriada de laboratório, a partir de experiências culturais situadas, não acontece como algo delimitado em um espaço, mas ao assimilar a síntese mesma do bairro, um "territóriolaboratório". Nele, a inovação emerge historicamente a partir das necessidades da população, em que se empregam táticas de hacking eletrônico e gambiarras. Eles estabelecem o que chamam de "tecidos de confiança" com coletivos e instituições, desenvolvendo trabalhos conjuntos e gerando um intercâmbio refletido no resultado da produção. Isso porque, apesar de um pouco incompreensíveis para a população, "estamos começando a abrir a fronteira, o laboratório tem que ir mais para lá".

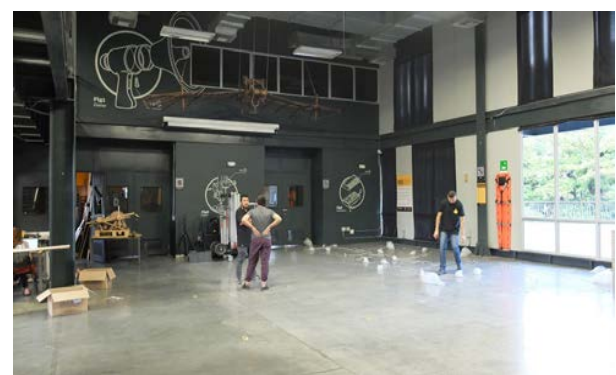

Figura 6: Interior do "Exploratorio", com espaço sendo preparado para uma instalação artística, e salas ao fundo com máquinas.

\section{SÍNTESE DOS RESULTADOS}

Após a caracterização geral dos casos, vale destacar tópicos significativos para a melhor compreensão dos mesmos, e para a singularização de cada um dos laboratórios. As informações estão organizadas nas tabelas abaixo, e são complementadas por breves desdobramentos explicativos.

Tabela 1: Características principais de cada laboratório

\begin{tabular}{|l|l|l|l|}
\hline $\begin{array}{l}\text { Laboratórios/ } \\
\text { características }\end{array}$ & Tipo & Localização & Identidade \\
\hline $\begin{array}{l}\text { Fábrica diseño } \\
\text { e inovación }\end{array}$ & Concentrado & $\begin{array}{l}\text { Polo de } \\
\text { divulgação } \\
\text { cientíica }\end{array}$ & $\begin{array}{l}\text { Laboratório de } \\
\text { soluções de } \\
\text { design em } \\
\text { projetos e } \\
\text { serviços }\end{array}$ \\
\hline $\begin{array}{l}\text { Fab Lab Livre } \\
\text { SP }\end{array}$ & $\begin{array}{l}\text { Sistema } \\
\text { distribuído / } \\
\text { ramificado }\end{array}$ & $\begin{array}{l}\text { Centros } \\
\text { Educacionais, } \\
\text { Centros } \\
\text { Culturais }\end{array}$ & $\begin{array}{l}\text { Laboratório de } \\
\text { formação e } \\
\text { plataforma } \\
\text { para acesso } \\
\text { livre às } \\
\text { tecnologias }\end{array}$ \\
\hline Exploratorio & Concentrado & $\begin{array}{l}\text { Parque de } \\
\text { ciência e } \\
\text { tecnologia }\end{array}$ & $\begin{array}{l}\text { Laboratório de } \\
\text { participação } \\
\text { cidadã } \\
\text { multidisciplinar } \\
\text { de práticas } \\
\text { reflexivas }\end{array}$ \\
\hline
\end{tabular}

A "Fábrica" tem suas atividades concentradas em um único local, no qual toda a infraestrutura, ferramentas e máquinas estão disponíveis. Contudo, ela está localizada em um espaço de acesso regulado, em uma área distanciada da região central. O "Fab Lab Livre" já nasceu sob uma infraestrutura base de inclusão digital e, 
consequentemente, em uma rede por natureza, devido à herança dos Telecentros. Desse modo, consegue se inserir em contextos muito periféricos e distantes no município, e que, ao mesmo tempo, mantém unidades centralizadas. O "Exploratorio" surge por uma oportunidade de campo, que foi a construção de uma nova edificação em uma proposta de reestruturação da área, parte de um plano urbano municipal. Assim, as atividades acontecem inseridas e dialogando com outras operações nesse conjunto, mas não se restringindo a ele, pois agrega distintas funções do e no território urbano.

Tabela 2: Vinculação e atividades inerentes

\begin{tabular}{|l|l|l|l|}
\hline $\begin{array}{l}\text { Laboratórios/ } \\
\text { características }\end{array}$ & $\begin{array}{l}\text { Vínculos } \\
\text { institucionais }\end{array}$ & $\begin{array}{l}\text { Agentes } \\
\text { envolvidos }\end{array}$ & $\begin{array}{l}\text { Atividades } \\
\text { oferecidas }\end{array}$ \\
\hline $\begin{array}{l}\text { Fábrica diseño } \\
\text { e inovación }\end{array}$ & $\begin{array}{l}\text { MCTI / } \\
\text { COFECyT }\end{array}$ & $\begin{array}{l}\text { Estudantes } \\
\text { UBA, } \\
\text { comunidade, } \\
\text { agentes } \\
\text { públicos }\end{array}$ & $\begin{array}{l}\text { Cursos de } \\
\text { capacitação; } \\
\text { Oficinas de } \\
\text { criação }\end{array}$ \\
\hline $\begin{array}{l}\text { Fab Lab Livre } \\
\text { SP }\end{array}$ & $\begin{array}{l}\text { Prefeitura de } \\
\text { São Paulo; } \\
\text { ITS Brasil; } \\
\text { 011.lab }\end{array}$ & $\begin{array}{l}\text { Estudantes, } \\
\text { pessoas de } \\
\text { comunidades } \\
\text { próximas }\end{array}$ & $\begin{array}{l}\text { Cursos de } \\
\text { capacitação; } \\
\text { Oficinas de } \\
\text { criação; } \\
\text { Residências }\end{array}$ \\
\hline Exploratorio & $\begin{array}{l}\text { Alcadia de } \\
\text { Medellin; } \\
\text { Ruta N; } \\
\text { iNNpulsa }\end{array}$ & $\begin{array}{l}\text { Coletivos e } \\
\text { pessoas de } \\
\text { comunidades } \\
\text { próximas }\end{array}$ & $\begin{array}{l}\text { Cursos de } \\
\text { capacitação; } \\
\text { Oficinas de } \\
\text { criação; } \\
\text { Residências; } \\
\text { Eventos e } \\
\text { instalações }\end{array}$ \\
\hline
\end{tabular}

A "Fábrica" tem vínculo direto com um órgão estatal de fomento à ciência, geralmente envolvendo atores especializados nas atividades de design, que estão direcionadas a pessoas envolvidas com setores específicos da sociedade. O "Fab Lab Livre" funciona mediante um vínculo misto com uma OSCIP (organização da sociedade civil de interesse público) e relações com um laboratório de inovação no setor público, permitindo acesso livre a usuários proponentes de atividades de formação e de projetos. O "Exploratorio" opera como oficina pública em cooperação com agências públicas de empreendedorismo e inovação, organizando suas atividades e o acesso do público em uma ampla gama de categorias, com formação, grupos de trabalho fixos, residências artísticas e eventos culturais.
Tabela 3: Divulgação de informaç̧̃es, atividades e projetos

\begin{tabular}{|l|l|l|l|}
\hline $\begin{array}{l}\text { Laboratórios/ } \\
\text { características }\end{array}$ & $\begin{array}{l}\text { Meios de } \\
\text { divulgação }\end{array}$ & $\begin{array}{l}\text { Repositório de } \\
\text { projetos }\end{array}$ & $\begin{array}{l}\text { Exemplos de } \\
\text { projetos }\end{array}$ \\
\hline $\begin{array}{l}\text { Fábrica diseño } \\
\text { e inovación }\end{array}$ & $\begin{array}{l}\text { Facebook, } \\
\text { Youtube e } \\
\text { Instagram }\end{array}$ & $\begin{array}{l}\text { Armazenamen } \\
\text { to digital em } \\
\text { drive com } \\
\text { fichas técnicas } \\
\text { de acesso } \\
\text { aberto }\end{array}$ & $\begin{array}{l}\text { "Sistemas } \\
\text { constructivos", } \\
\text { "yo digital", } \\
\text { "Proyectos } \\
\text { replicables" }\end{array}$ \\
\hline $\begin{array}{l}\text { Fab Lab Livre } \\
\text { SP }\end{array}$ & $\begin{array}{l}\text { Website, } \\
\text { Facebook, } \\
\text { Instagram e } \\
\text { Youtube }\end{array}$ & $\begin{array}{l}\text { Registro no } \\
\text { website de } \\
\text { imagens e } \\
\text { arquivos de } \\
\text { acesso aberto }\end{array}$ & $\begin{array}{l}\text { "Togotoy", } \\
\text { "Espaço ZEN" } \\
\text { Heliópolis }\end{array}$ \\
\hline Exploratorio & $\begin{array}{l}\text { Website, } \\
\text { Twitter, } \\
\text { Facebook, } \\
\text { Instagram e } \\
\text { Youtube }\end{array}$ & $\begin{array}{l}\text { Não possui } \\
\text { repositório } \\
\text { aberto. } \\
\text { Registro de } \\
\text { atividades no } \\
\text { website }\end{array}$ & $\begin{array}{l}\text { "Dispositivo de } \\
\text { rádio móvel" } \\
\text { Colectivo } \\
\text { Manzana } \\
\text { Radio }\end{array}$ \\
\hline
\end{tabular}

Os três laboratórios utilizam mídias digitais para divulgar suas agendas, informações básicas, algumas imagens e descrições sobre as atividades e a produção. Contudo, o armazenamento de projetos acontece com registros técnicos e de modo mais formalizado pela "Fábrica". O "Fab Lab Livre" depende dos arquivos fornecidos pelos próprios usuários, por isso, muitas das informações sobre os projetos não estão completas. O "Exploratorio" está desenvolvendo um repositório próprio acessível ao público, para o arquivamento dos projetos gerados. Os projetos desenvolvidos, alguns deles citados aqui a título de exemplo, envolvem estratégias de inovação social ao articularem demandas comunitárias, como o artefato "yo digital" e sua interface para ensino lúdico de sistemas digitais para idosos; o "togotoy" como blocos modulares que integram, pelo alfabeto, crianças com deficiência visual e crianças videntes; o "Dispositivo de rádio móvel" que origina uma plataforma aberta para a comunicação sonora em espaços públicos.

\section{DISCUSSÃO}

A expansão do modelo "Fab Lab" ao mundo serviu como fonte de difusão cultural de um modus operandi engendrado, como tantos outros, advindo dos Estados Unidos. Isso inclui a referência constante, por quem o adota, a uma Instituição reconhecida no meio acadêmico, além da divulgação, de maneira privilegiada, do catálogo de empresas que fabricam e vendem máquinas $\mathrm{CNC}$ e outros equipamentos que pertencem ao kit divulgado para o pleno funcionamento dos Fab Labs. Aos poucos, os próprios Fab Labs estabelecidos pelo mundo buscaram alternativas às tecnologias oferecidas e adaptá-las ou adquirir versões mais acessíveis. Com essas pequenas alterações, os próximos passos naturalmente seriam relacionados a se repensar os tipos de espaços e atividades oferecidas.

Seria o caso de, em nossos contextos, nos orientarmos pela noção de adequação sociotécnica, que "pode ser entendida - em termos normativos - como um processo no qual um dispositivo tecnológico passaria por um processo de adaptação aos interesses políticos de grupos sociais relevantes diferentes dos que a originaram" (Dagnino, 2009 , p. 123). Para constituir uma nova visão sobre o assunto, é necessária "a inclusão social e o empoderamento de atores sociais que buscam uma nova lógica para a relação ciência-tecnologia-sociedade" 
(Dagnino, 2009, p. 143). Complementarmente, são as ações de desenvolvimento local que deveriam orientar as agendas de investigação e inserção das novas dinâmicas de participação e criação a longo prazo.

Se, no início do século, Neil Gershenfeld (2005) apontava para os benefícios da fabricação pessoal, hoje essa visão um tanto encantadora acerca dos laboratórios já tem o seu brilho e efetividade abrandado em nossa região - como mostram as várias realidades que temos pesquisado, indicando um baixo crescimento de Fab Labs instalados em relação ao mundo, já que a implementação das tecnologias acontece de modo mais sustentado nas instituições acadêmicas (Scheeren et al., 2019). Cabe explorarmos não uma visão linear acerca da aplicação das tecnologias, mas acessar abordagens teóricas mais contextualizadas e de acordo com empregos significativos para cada região, seus setores de investigação e de produção.

O trabalho elaborado pelos laboratórios apresentados nas cidades da Argentina, do Brasil e da Colômbia, direciona as atividades para as devidas comunidades, continuando com a aplicação das práticas "faça você mesmo", mas aprofundando $\mathrm{o}$ atendimento às demandas de setores produtivos e da sociedade civil, partindo de dinâmicas orientadas à resolução de problemas locais com ativa participação coletiva, evitando práticas individualizadas. Os laboratórios estudados são relevantes incubadoras de projetos criados por distintas agências de inovação governamentais. Desse modo, exercem um papel importante em seus contextos para uma ampla e complexa mudança nos modelos de articulação com atores institucionais e na produção distribuída, por meio de oficinas, residências e espaços de formação. $\mathrm{O}$ acesso aos espaços não se restringe a quem irá utilizá-los para fabricar, mas importam também os processos, trocas e conhecimentos adquiridos, "como ambientes de aprendizagem multidisciplinar" (Walter-Herrmann; Büching, 2013, p. 28).

A análise dos três laboratórios deve ser feita a luz das suas condições de implantação, tanto territoriais quanto de políticas culturais. A "Fábrica Diseño e Innovación" foi criada como centro estratégico para aproveitar expertise técnica acumulada nas instituições públicas de ensino superior e direcioná-las para solucionar demandas muito variadas, fomentando o desenvolvimento tecnológico interno do país. O "Fab Lab Livre SP", que foi criado sob decisão da gestão da prefeitura municipal da época por meio da adaptação e atualização de estruturas de formação vigentes, vislumbrando o potencial de ação descentralizado dos laboratórios, atua em regiões de maior necessidade sócio-econômica ou com acesso estratégico. O "Exploratorio: taller público de experimentación", que se instaurou e evoluiu fruto do trabalho colaborativo de um conjunto de agentes públicos e coletivos culturais, atribui grande relevância aos interesses advindos de comunidades informais da cidade.

A similaridade existente entre os três é o de potencializar a abordagem de processos de inovação social, agenciadas por meio de políticas públicas. A democratização do acesso a esses locais não se apresenta, entretanto, como condição suficiente para a materialização de artefatos de significativo impacto para as pessoas e o contexto. Para isso, depende de projetos consistentes, associações colaborativas fortes com a comunidade e processos de investigação conjunta com especialistas e não-especialistas. A dificuldade encontrada por eles está em evitar a mera reprodução de ideias já existentes no meio digital, assim, fomentando procedimentos de criação de projetos próprios.

Nesse sentido, plataformas de compartilhamento aberto de arquivos acabam por cumprir uma função ambígua: ao mesmo tempo em que facilitam o acesso, implicam numa limitação ao proporcionar uma fácil replicação, já que a alteração e aprimoramento dos projetos exige conhecimento técnico e operacional. Nota-se que a base de uma implementação pública e de acesso com suporte de atores com conhecimento técnico é fundamental para construir ativamente com a tecnologia (Blikstein \& Krannich, 2013). Além desse aspecto, a dedicação de tempo necessário para se alcançar um nível melhor elaborado de propostas também é um fator limitante para os laboratórios.

Portanto, não basta somente falarmos em empoderamento dos usuários pelo conhecimento construído nesses locais, mas de que modo é possível que estes espaços se tornem efetivamente atrativos, para que os mesmos se apropriem de sua dinâmica de funcionamento e possibilidades de fabricação. O valor de inovação, nesses casos, não dependerá de processos desenvolvidos unicamente nos laboratórios, mas da maneira como cada um deles se expande em conjunto com coletivos, setores produtivos e trabalhadores de outras áreas. Logo, o desafio é incluir agentes externos e desdobrar projetos com base na participação e por meio de processos de investigação por períodos prolongados. Tais planos estão no horizonte do "Fab Lab Livre SP" e do "Exploratorio: taller público de experimentación", já que na "Fábrica Diseño e Innovación", os procedimentos são instituídos com base nas pontuais demandas externas.

O "Fab Lab Livre SP" procura, desde a sua fundação, estar alinhado aos princípios do modelo "Fab Lab", mas percebendo que, no contexto brasileiro, a sua inserção e ventura depende de estratégias de envolvimento ativo e respostas eficazes em relação ao que é produzido nesses locais. A "Fábrica Diseño e Innovación" designa um modelo relacionado às incubadoras tecnológicas, a partir do qual seu espaço é utilizado para a elaboração de projetos com bases metodológicas reconhecidas pelos profissionais envolvidos, com nível de conhecimento técnico adequado para coordenar o serviço do início ao fim. O "Exploratorio: taller público de experimentación" tem um funcionamento mais informal, promovido pela equipe para tentar quebrar barreiras com o público, as quais se estabelecem devido à visão corrente acerca do ambiente hermético das instituições.

Para se tornarem efetivos os procedimentos de abertura dos espaços, a divulgação dos projetos é muito importante, não apenas para apresentá-los ao público geral, mas com a finalidade de torná-los compreensíveis e estimular a aproximação das comunidades às novas tecnologias e aos outros espaços de criação. Os processos de identificação do público emergem pelo reconhecimento de estruturas estranhas a sua realidade, e que contribuem na conformação dos sujeitos por meio de sistemas de produção e de aprendizado. No caso, as tecnologias disponíveis acabam exercendo um papel de abertura para perspectivas futuras profissionais, mas também para colocar a imaginação em prática. Além disso, são espaços de formação pelas suas dinâmicas de receptividade e 
abertura, tanto pelas pessoas que lá trabalham ou participam, quanto pelas ideias muito singulares de atividades propostas, que dificilmente aconteceriam em outros locais.

O processo de identidade dos laboratórios passa por uma constituição que acontece em relação a, por vezes, atentarse às características do modelo Fab Lab, mesmo que num horizonte distante, mas sem perder de vista o que está mais próximo. A Fábrica não deixa de ter um papel crucial ao promover a imersão dos envolvidos na investigação e aprimoramento de projetos. O Exploratorio se distancia da ideia de um espaço formal, com outros saberes e formas de trabalhar distantes da ciência codificada, se aproximando das comunidades nas quais está inserido e procurando se moldar a partir das necessidades e dinâmicas específicas daquele lugar, como é o caso do bairro Moravia (Uribe Zapata, 2018). Como citam Dias e Smith, (2018), nas unidades periféricas do Fab Lab Livre, o tom está em desempenhar um papel como espaço para as pessoas se reunirem e exercitarem seu potencial criativo, conectando os problemas de um determinado território a soluções viáveis, geradas pelas próprias comunidades, encontrando respostas endógenas e sustentáveis para os problemas sociais, econômicos, ambientais e políticos que enfrentam, uma "materialidade da inclusão".

\section{CONCLUSÃO}

O que foi apresentado pretende ser um registro e divulgação de outros modos de conformação de laboratórios que utilizam tecnologias digitais em nossa região. Como vimos, na Fábrica o seu uso é complementar, no Exploratório é eventual, e apenas no homônimo Fab Lab permanece como um elemento estruturador das atividades. As práticas e o impacto (Meninchinelli, 2017) dos laboratórios mencionados, em cada contexto, apresentamse, ainda, em níveis experimentais, nos seguintes aspectos: aprimoramento da participação e envolvimento dos usuários, fomento da autonomia em processos de aprendizagem técnica e de projeto, e disseminação de conhecimento adquirido para a inovação em seus próprios termos.

Em contrapartida, contam com a formação de redes (Manzini, 2014) contextualizadas de conhecimento e participação, que contribuem para o invocar sentidos muito diversos de comunidade. A partir dos casos apresentados, percebemos que a consolidação dos princípios democráticos e inclusivos do "Fab Lab", e o avanço para além deles em iniciativas geridas por organismos governamentais ou mistos, está mais dependente das práticas contínuas e das articulações estratégicas do que do espaço de formação e de suas tecnologias digitais. Ao final, em termos de produção, os espaços não deixam de utilizar estratégias tais como a gambiarra, ressignificando práticas que já estavam presentes no cotidiano.

Futuras investigações podem ser realizadas de modo aprofundado em cada laboratório, por meio de acompanhamento continuado de uma série de atividades e estudos etnográficos. À parte disso, os métodos e resultados apresentados nesse trabalho podem servir de base para estudos similares em relação a outros conjuntos de laboratórios.

\section{AGRADECIMENTOS}

Processo n 2017/04946-7, Fundação de Amparo à Pesquisa do Estado de São Paulo (FAPESP). Aos representantes e colaboradores dos laboratórios que contribuíram por meio das entrevistas, respondendo o questionário e enviando material de divulgação: Rita Wu pelo Fab Lab Livre SP, Heidi Jalkh e Silvina Papasaragas pela Fábrica, Camilo Cantor e Laura Isabel Luna Cano pelo Exploratorio.

\section{REFERÊNCIAS}

Blikstein, P., \& Krannich, D. (2013). The makers' movement and fablabs in education: Experiences, technologies, and research. In ACM International Conference Proceeding Series (pp. 613616). https://doi.org/10.1145/2485760.2485884

Dagnino, R. (Org.) (2009). Tecnologia social: ferramenta para construir outra sociedade. Campinas: IG/UNICAMP.

Dias, R., \& Smith, A. (2018). Making in Brazil: Can we make it work for social inclusion?. Journal of Peer Production, 12, 43-59.

Fab Wiki. (n.d.). Retirado de http://wiki.fablab.is/wiki/Main_Page

Fonseca de Campos, P. E., \& Dias, H. J. D. S. (2018). A insustentável neutralidade da tecnologia: o dilema do Movimento Maker e dos Fab Labs. Liinc Em Revista, 14(1). https://doi.org/10.18617/liinc.v14i1.4152

García Canclini, N. (2015). Culturas híbridas: estratégias para entrar e sair da modernidade. São Paulo: Edusp.

Gershenfeld, N. (2012). How to make almost anything: the digital fabrication revolution. Foreign Affairs, V. 91, n. 43, nov./dez. 2012, p. 43-57.

(2005). FAB: The Coming Revolution on Your Desktop - From Personal Computers to Personal Fabrication. Basic Books.

Herrera, P., \& Juárez, B. (2012). Perspectivas en los Laboratorios de Fabricación Digital en Latinoamérica. In Proceedings of the 16th Iberoamerican Congress of Digital Graphics, Fortaleza 285-289.

Lune, H., \& Berg, B. L. (2017). Qualitative Research Methods for the Social Sciences. Essex: Pearson.

Meninchinelli, M. (2017). Notes for future research on the impact of the Fab Lab network. In A. Briceño, \& T. Vivanco (Eds.) Research Book - Fabricating Society: 13th International Fab Lab Conference and symposium. Santiago: S.E., 34-44.

Manzini, E. (2015). Design when everybody designs: an introduction to design for social innovation. Cambridge: MIT Press

Manzini, E. (2014). Making Things Happen: Social Innovation and Design. Design Issues, 30(1), 57-66. https://doi.org/10.1162/desi_a_00248

Mignolo, W. D. (2008). Desobediência epistêmica. Cadernos de Letras da UFF, 34, 287-324.

Mignolo, W. D.; \& Walsh, C. E. (2018). On decoloniality: concepts, analytics, praxis. Duke University Press.

Mortara, L., \& Parisot, N. G. (2016). Through entrepreneurs' eyes: the Fab-spaces constellation. International Journal of Production Research, 54(23), 7158-7180. https://doi.org/10.1080/00207543.2016.1198505

Nascimento, S. (2014). Critical Notions of Technology and the Promises of Empowerment in Shared Machine Shops. Journal of Peer Production, 5, 1-5.

Scheeren, R., Herrera, P. \& Sperling, D. (2019). Evolving stages of digital fabrication in Latin America - Outlines of a research and extension project. In Proceedings of the 37th eCAADe and 23rd SIGraDi Conference - Volume 2, Porto, 797-806. https://doi.org/10.5151/proceedings-ecaadesigradi2019_519 
Soderberg, J. (2013). A ilusória emancipação por meio da tecnologia. Le Monde Diplomatique Brasil. Retrieved from http://diplomatique.org.br/a-ilusoria-emancipacao-por-meioda-tecnologia/

Sperling, D., Herrera, P., Celani, G., \& Scheeren, R. (2015). Fabricação digital na América do Sul: um mapeamento de linhas de ação a partir da arquitetura e urbanismo. In Proceedings of 19th Iberoamerican Congress of Digital Graphics, Florianópolis,

119-125. https://doi.org/10.5151/despro-sigradi2015-30212

Troxler, P. (2016). Fabrication Laboratories (Fab Labs). In J. P. Ferdinand, et al. (Eds.), The Decentralized and Networked
Future of Value Creation (pp. 109-127). Basel: Springer https://doi.org/10.1007/978-3-319-31686-4_6

Uribe Zapata, A. (2018). El Exploratorio, un laboratorio ciudadano en Medellín-Colombia. Trilogía Ciencia Tecnología Sociedad, 10(18), 117-131. https://doi.org/10.22430/21457778.667

Walter-Herrmann, J., \& Büching, C. (Ed.) (2013). FabLab: Of Machines, Makers, and Inventors. Wetzlar: Transcript-Verlag.

Wang, D., \& Groat, L. (2015). Architectural research methods (second edition). New Jersey: John Wiley and Sons 